\title{
Democracia caudillista y desmovilizaciones sociales en Ecuador
}

\author{
José Sánchez Parga*
}

\begin{abstract}
Resumen: Los conflictos y reivindicaciones de los movimientos sociales, políticamente representables, durante la transición democrática de los 80, entran en crisis con el modelo de acumulación y concentración de riqueza, inaugurado por la dominación neoliberal durante los 90, dando lugar al ciclo de movilizaciones de protesta, que agravan la crisis de todo el sistema de representación política (elecciones, partidos, congreso), el que degenera en un fenómeno nuevo: el representativismo político. El imperativo de "gobernabilidad" de la protesta, la acumulación y concentración de poderes ejecutivos, para un mejor gobierno económico de la política, reforzaron los poderes del hiperpresidencialismo y la formación de una democracia caudillista, que en Ecuador adoptó una orientación contraneoliberal.

Palabras clave: Democracia, representación y representativismo políticos, hiperpresidencialismo, caudillismo, movimientos sociales, movilizaciones políticas, conflicto y protesta.
\end{abstract}

\section{"Caudillista" democracy and social demobilizations in Ecuador}

\begin{abstract}
The conflicts and vindications of the social movements, with politically representation, during the democratic transition of the 80's, enter crisis with the model of accumulation and concentration of wealth, inaugurated by the neoliberal domination during the 90's, giving rise to the cycle to the protest mobilizations, that aggravate the crisis of all the system of political representation (elections, parties, congress), which degenerates in a new phenomenon: the political representativism. The imperative of "governability" of the protest, the accumulation and concentration of executive power, for a better economic government of politics, reinforced the powers of hiperpresidencialism and the formation of a "caudillista" democracy, that in Ecuador adopted a counter-neoliberal orientation

Key words: Political democracy, representation and social representativism, hiperpresidencialism, “caudillismo”, social movements, political mobilizations, conflict and protest.
\end{abstract}

\section{Democracia caudillista e desmovilizaciones sociais em Equador}

Resumo: Os conflitos e reivindicações dos movimentos sociais, politicamente representables, durante a transição democrática dos 80, entram em crises com o modelo de acumulación e concentração de riqueza, inaugurado pela

\footnotetext{
* Universidad Politécnica Salesiana; Quito, Ecuador. Email: jsanchezp@ups.edu.ec
} 
dominación neoliberal durante os 90, dando lugar ao ciclo de mobilizações protestarias, que agravam a a crise de todo o sistema de representação política (eleições, partidos, congresso), o que degenera num fenômeno novo: o representativismo político. O imperativo de "gobernabilidade" do protesto, a acumulação e concentração de poderes executivos, para um melhor governo econômico da política, reforçaram os poderes do hiperpresidencialismo e a formação de uma democracia caudillista, que em Equador adotou uma orientação contraneoliberal.

Palavras-chave: Democracia, representação e representativismo políticos, hiperpresidencialismo, caudillismo, movimentos sociais, mobilizações políticas, conflito e protesto.

Recibido: 02.10.2009

Aceptado: 26.10.2009

La crisis del sistema de la representación política (sistema de partidos, electoral y parlamentario), que degeneró en un representativismo político, combinada con una creciente concentración y acumulación de poder en el Ejecutivo, ambos procesos convergentes en una mayor personalización del poder presidencial, han dado lugar en Ecuador, como en otros países de América Latina, a una democracia caudillista, donde la representación política de los ciudadanos parece haber sido sustituida por una conducción política de los gobernantes.

Este fenómeno está muy marcado por los nuevos gobiernos contraneoliberales, exponentes de las movilizaciones sociales frente a la dominación neoliberal, y que han sido capaces de interpretar y conducir el ciclo de protestas, que ocuparon el escenario político de las últimas décadas.

Simultáneamente se ha observado una transformación de los movimientos sociales, que en los años 80 protagonizaron los conflictos reivindicativos y que en los 90 se convirtieron en movilizaciones de protesta. En la actualidad dichos movimientos conflictivos y protestatarios se encuentran en un proceso de desmovilización, en parte debido a su conversión en fuerzas y partidos políticos, en parte cooptados por los gobiernos caudillistas, en parte desgastados por las limitaciones impuestas a sus reivindicaciones y protestas, y finalmente en parte atrofiados por las violencias sociales, que cada vez se imponen bajo la forma más visible de las delincuencias y criminalidades.

\section{De la representación política a la representatividad de los políticos}

La penetración del mercado en la política privatiza la representación política y la atraviesa por la ley de la oferta y la demanda, transformándola en una representación delegativa, y por consiguiente clientelar, sujeta a un proceso constante de corrupción: la representación política, que 
es esencialmente pública, se corrompe al privatizarse. Aunque ya bajo el gobierno de Febres Cordero (1984-88) se inicia la compra de los primeros votos parlamentarios y de diputados, la corrupción se agravará todavía más durante los años 90: cuando el Vice-Presidente Dahik (1994) el más neoliberal de los gobernantes es enjuiciado y censurado por corrupción en el Congreso.

La Constitución de 1998 asesta un duro golpe a la representación política, al integrar el Congreso con diputados elegidos por cada provincia (art. 126), eliminándose así los diputados nacionales. Aunque se establece que "actuarán con sentido nacional” (art. 135), tal recomendación no garantiza que su representación política sea nacional. De otro lado los diputados ya no actúan dependientes de un partido (art. 56) y su nueva condición de "independientes", outsiders, hace que ya no sea su perfil político sino su personal perfil privado o profesional, lo que los convierte en representativos para la política

Esta versión delegativa de la representación política se corrompe aún más, cuando la representatividad personal de los diputados se impone sobre el ejercicio de su representación política. Esto modificará la misma sociología de los parlamentarios y amentará todavía más su venalidad ${ }^{1}$. Los diputados dejan de ser comprados por el Ejecutivo, ya que ellos mismos comienzan a ponerse en venta. Si la representación parlamentaria se degrada, es porque deja de estar mediatizada por la representación política ejercida por los partidos: al legalizarse (Constitución de 1998) la situación de hecho de "candidatos independientes" (no sólo de vínculos partidarios sino también parlamentarios), los diputados se vuelven presa del mejor postor. Tal cambio golpeó también duramente al sistema de partidos. La convergencia de la delegación y la transferencia de la representación política a la persona del representante darán lugar a un nuevo fenómeno: la representatividad (privada y personal) de los políticos en la democracia moderna, factor a su vez decisivo en la democracia caudillista, donde se conjuga un fuerte representatividad del Presidente y su conducción gubernamental, condensando en su persona representación y representatividad políticas.

La representación política ha perdido su objeto o contenido ante la incapacidad de definir e identificar el bien común o interés colectivo en la sociedad nacional. A la "estructural heterogeneidad" de las sociedades latinoamericanas, que siempre dificultó la identificación de intereses comunes y de un bien colectivo ampliamente compartidos por las diferentes clases, grupos y sectores sociales, se añaden durante la década de los 80 y 90 una serie de factores y procesos tendientes a segmentar todavía más dichas sociedades, atravesarlas por crecientes desigualdades, reducir o di-

\footnotetext{
${ }^{1}$ Sobre los rasgos políticos y personales de los diputados ecuatorianos y su comparación con el promedio latinoamericano en los años 90 puede consultarse el estudio publicado por el CIS / AECI / Universidad de Salamanca, Elites parlamentarias. Ecuador, vol. 4, Madrid, 1998.
} 
solver más aún los intereses comunes y necesidades colectivamente compartidas.

En primer lugar, las políticas y programas de privatización de lo público contribuyeron no sólo a reducir los bienes y recursos comunes en la sociedad sino también a desarrollar una ideología y valoración de lo privado en detrimento de todos los bienes, servicios y proyectos públicos de la sociedad. En este proceso converge el desarrollo y consolidación de una sociedad de mercado, esencialmente incompatible con todo lo que pueda ser común y público, que tienden a quedar progresivamente disueltos por las fuerzas y lógicas de la oferta y la demanda mercantiles. En este contexto la ideología neoliberal ejerce una influencia decisiva, para que el bien común se haga mal común y que "nada en común” se vuelva el ideal de una sociedad sin socialidad alguna ${ }^{2}$. Si por consiguiente el bien común no existe, tampoco serían posibles diferentes versiones de su representación política ${ }^{3}$. Lo público es políticamente sinónimo del interés común y de lo colectivo; por ello la crisis y ocaso de la representación política se reduce en última instancia a la crisis y desaparición de lo público; en la medida que es privatizado su representación política se vuelve imposible. A diferencia de lo que ocurre en la esfera de lo privado y del mercado, "lo público es afirmación de una unidad” y soporte de un orden compartido, el cual transciende las desigualdades, y en cuanto "exterior y superior a los individuos lo público es una relación impersonal” y por consiguiente nunca puede ser objeto de una contractualidad cualquiera que sea, y por esta misma razón necesariamente es siempre objeto de una representación ${ }^{4}$.

En segundo lugar, la “década de la pobreza” inaugura en los 90 un proceso de creciente inequidad y exclusión social, radicalizando aún más las diferencias y segmentaciones al interior de la sociedad, ampliando las brechas entre minorías cada vez más ricas y mayorías cada vez más pobres; tales polarizaciones extremas volvieron imposible la identificación de intereses comunes, de proyectos compartidos, objeto de la más mínima participación colectiva al interior de la sociedad. Una particularidad de este proceso fue el eclipse de las clases medias, su achicamiento, segmentación interna, pérdida de cohesión y visibilidad, de identidad, de hegemonía y sobre todo de posicionamientos sociales. La clase media siempre fue el sector privilegiado no sólo para amortiguar las luchas de clases, atenuar las

\footnotetext{
2 Para Aristóteles, quien nada tenía de comunista y prefería "menos en común” que “demasiado en común”, ninguna sociedad sería posible ni podría subsistir "sin algo en común” (cfr. Politica, II, 1260 b, 39ss).

3 "La República está muerta: el bien común ya no prevalece"; puesto que "La idea republicana implica que el Bien común prevalece sobre el bien individual” (Matthieu Baumier, La démocratie totalitaire. Penser la modernité post-démocratique, Presses de la Renaissance, Paris, 2007:54; 56).

${ }^{4}$ Cfr. Julien Freund, L'essence du politique, Sire, Paris, 1986:320ss. Es importante la distinción que Rousseau establece entre "la voluntad colectiva y la voluntad general; esta no considera más que el interés común, la otra el interés privado, que no es más que la suma de voluntades particulares” (J. - J. Rousseau, Du Contrat Social, lib. II, cap. III).
} 
contradicciones extremas a su interior, sino también para producir su mayor cohesión interna, sobre todo el lugar de definición y elaboración del bien común, de los intereses más y mejor compartidos por la totalidad de la sociedad. Por todo esto la clase media era siempre la que mejor podía ser políticamente representada; su crisis entendida como crisis de sociedad tendrá un efecto profundo, al repercutir en las condiciones de posibilidad de la representación política.

La convergencia por un lado de una disolución de toda res publica, del bien común, con la fracturación de la sociedad, ruptura de sus vínculos y cohesiones internas, y por otro lado las fuerzas descentralizadoras, regionalistas, localistas y autonomistas, darán lugar a neocomunitarismos y etnicismos, que además de particularizar el bien común, reduciéndolo a necesidades particulares, tenderá a hacer más microfísicos, faccionalistas y privados los intereses colectivos. Todo lo cual terminará despojando la representación política de finalidad y contenido.

Ya a mediados de los 90 O’ Donnell señalaba un cambio radical en la representación política, expresión de un nuevo modelo de “democracia delegativa”. Se trataba entonces de conceptualizar una representación política, que en sus presupuestos y procedimientos de derecho público se transformaba en una modelo de repesentación característico del derecho privado, haciendo que los representantes políticos, actuaran como simples abogados de intereses particulares; que lejos de responder al bien común y al interés público y colectivo de toda la sociedad, aparecieran más bien sujetos a una suerte de contractualidad de servicios privados; sujetos a sus representados, ante los cuales deberían rendir cuentas ${ }^{5}$. Es cuando se vulgariza la idea de accountability.

En la práctica la “representación delegativa”, que obligaría a los representantes a actuar de acuerdo a un "mandato imperativo” de sus representados, no es más que una ficción, un artificio, quizás peor una impostura o una corrupción, en la medida que no se puede instaurar un modelo de representación de derecho privado en un contexto institucional de derecho público y político, como es el régimen democrático. Lo que no dejará de provocar conflictos y malentendidos muy contraproducentes para la democracia actual. En el transcurso del siglo XIX la influencia del liberalismo atribuye un mayor predominio a lo privado, y tenderá a identificar delegación y representación; pero durante las últimas décadas bajo el dominio neoliberal la representación delegativa termina imponiéndose sobre la política, convirtiéndose en normativa; lo que a su vez confunde lo privado con lo público. Por eso "la lucha por la representación es siempre una lucha por el poder político”6.

Esta situación se agrava durante las dos últimas décadas por efecto del discurso neoliberal, e incluso por la pobretología o ideología sobre la

\footnotetext{
${ }^{5}$ Guillermo O’ Donnell, “Delegative Democracy”, Journal of Democracy, n. 5, 1994:56-69.

${ }^{6}$ Carl Schmitt, Die Diktatur, Berlin, 1963, 212.
} 
pobreza, que coinciden en traducir los intereses sociales en necesidades sociales, con una desgraciada consecuencia: mientras que los intereses poseen una objetividad social y por consiguiente pueden ser colectivamente compartidos, y también por ello políticamente representables, las necesidades por el contrario son siempre particulares, subjetivas, por consiguiente no compartidas, y al pertenecer al imaginario social, al orden del deseo, tampoco pueden ser objeto de una representación política. También en este contexto se enmarca el síndrome del clientelismo neo-populista ${ }^{7}$.

Además de transformar sustantivamente la relación entre el pueblo y sus representantes políticos, este cambio repercutió en todas las otras instituciones y prácticas de la representación política: en el Congreso la deliberación parlamentaria para la producción del bien común e intereses colectivos degeneró en negociaciones entre partidos y diputados de intereses particulares y privados; los procesos y procedimientos legislativos perdieron transparencia pública, propiciando acuerdos ocultos, corrupción de las decisiones y venalidad de los diputados; los partidos políticos se fueron vaciando de sus especificidades y diferencias ideológicas, quedando reducidos a lobbies e intereses regionales y grupos de poder; el sistema electoral, permitiendo candidaturas de independientes y propiciando la regionalización y localización de candidatos, fomentó el clientelismo político.

Los partidos políticos siempre habían desempeñado una función fundamental en la representación política, al organizar y unificar la multiplicidad de fuerzas e intereses de la sociedad; en la medida que sus definiciones ideológicas y reagrupamiento de intereses contribuían a elaborar ya una versión o propuesta parcial del bien común e interés general de la sociedad, la cual podría convertirse en objeto de debates parlamentarios y de acuerdos legislativos con los otros partidos. Tal era la función del partido político: compartir opciones y alternativas sobre el interés general y participar en su elaboración y definición. Por el contrario, en el marco de una representación delegativa los partidos políticos se volverían incluso disfuncionales, puesto que en el Congreso se impondría la tendencia inversa: representación política de las minorías más diferentes y diversas, de los particularismos y de los intereses más dispares y contrapuestos, de las necesidades más incompatibles. Al no poder desempeñar dicha representación política, los partidos han tratado de compensar esta pérdida de poder ejerciéndolo en los otros organismos políticos del Estado, constituyéndose así en una partidocracia ${ }^{8}$. Al mismo tiempo que perdían su específico poder de "mediación" propia de la representación política en el Congreso, de servir de soporte a esa mediación entre representantes y representados, para

\footnotetext{
${ }^{7}$ Cfr. J. Sánchez Parga, “¿Por qué se deslegitima la democracia? El desorden democrático”, Ecuador Debate, n. 62, agosto 2004:77.

${ }^{8}$ Sobre la aparición de los “outsider” de la representación política en el Congreso y al margen de los partidos: cfr. Juán J. Linz, "Presidential or Parliamentary Democracy”, en Juan J. Linz \& Arturo Valenzuela, The Failure of Presidential Democracy, The Johns Hopkins University Press, Blatimore and London, 1994: 26ss.
} 
compensar tal pérdida de poder político, los partidos forman una partidocracia, que al margen de los ciudadanos y fuerzas sociales trata de lotear el Estado, repartirse y ocupar los cargos superiores en organismos políticos administrativos, en Tribunales como el Judicial y Electoral, funciones de fiscalización y control público. En definitiva el partido, “el principal mecanismo de la relación entre el ciudadano y el Estado”, deja de ser la institución que articula participación y representación política9 .

Todos estos fenómenos no sólo precarizan las prácticas parlamentarias, sino que incluso empeoran sociológicamente la misma clase política, en la medida que los diputados tendieron no sólo a reproducir la condición social de sus representados sino a convertirse en su identificación más imaginaria. Cuanto mayor es la integración social de una clase o sector de la sociedad más fácil y coherente resulta su representación política, pues su participación social forma parte del interés general y del bien común; por el contrario cuanto mayor es la marginalidad o exclusión social de una población mucho más difícil será su representación política asociada al interés general y a la participación en el bien común; por consiguiente con mayor fuerza e intensidad dichas poblaciones y sectores buscarán ser representados no ya delegativa sino imaginariamente, buscando y eligiendo como representantes aquellos con quienes más o mejor se identifican. Esta representación identificatoria, por la cual grupos y clases sociales tienden a proyectarse imaginariamente en sus representantes, adopta además la forma de una representación sociológica, tendiente a reproducir en el Congreso las mismas condiciones sociales de los representados; como si una tal reproducción garantizara una buena representación política.

Por muy paradójico que parezca, la configuración sociológica de los diputados en el Congreso, al mismo tiempo que suscita la peor opinión y valoración pública, sería sin embargo la que mejor refleja y expresa las condiciones sociales de la mayoría de sectores de la sociedad. Como si la sociedad rechazara tanto más aquella imagen de sus representantes políticos, cuanto más se viera reflejada y reproducida en ellos. No es casual que el candidato y representante político venga no de cualquier espacio público sino de aquellos propios del espectáculo (radial, televisivo, deportivo, de la farándula...). De esta manera, la representación clientelar se desdobla en una representación sociológica, mediante la cual los representados se proyectan imaginariamente (considerando lo imaginario siempre investido por el deseo) en sus representantes. Esto no sólo deforma políticamente la imagen de los representantes sino también pervierte sus actuaciones políticas, ya que ellos mismos aparecen representando no tanto lo que son sus representantes sino más bien lo que no son y quisieran ser.

Al quedar así sustituida la acción de representar políticamente el bien común e interés general de la sociedad por una relación entre representantes y representados, no sólo se escamotea el interés de todo lo que

${ }^{9}$ Cfr. Javier Tusell, La revolución posdemocrática, Edic. Nobel, Oviedo, 1997:236. 
puede ser públicamente compartido por todos los ciudadanos, sino que además se altera radicalmente la misma idea de una representación, que produce efectos (Vor-stellung), convirtiéndola en representación personal y teatral (Dar-stellung); creando con ello la ilusión de hacer presente el conjunto de la sociedad en el escenario político del Congreso. Nada menos casual, por ello, que los mass-media con sus personalidades más mediáticas aparezcan como el nuevo espacio y los nuevos protagonistas de la representación política, y que los mismos mass-media se encarguen de hacer representativos o investir de representatividad a los nuevos políticos; los cuales sólo existen políticamente en la medida que se vuelven mediáticos.

En la sociedad espectáculo, vaciada de toda ideología política, donde sólo se existe públicamente en la medida que se es visto y se es contemplado (el videor ergo sum), en la actual "sociedad teledirigida" del "homo videns" el político produce y sufre el síndrome Berlusconi, al confundir el hombre espectáculo con el hombre político, cuando en realidad se trata de dos dimensiones de lo público radicalmente opuestas ${ }^{10}$. Es así como los mass-media usurpan la representación política y en cierto modo suplantan y deslegitiman la de las instituciones democráticas (Congreso, diputados, partidos), al mismo tiempo que la modifican transformándola en representatividad política: quienes aparecen mediáticamente representativos, fácilmente se vuelven también políticamente representativos. El creer o imaginar que otro actúa y representa por nosotros, en nuestro lugar, provoca una ilusión política totalmente hipnótica, muchas veces reforzada por un clientelismo político más ilusorio que real ${ }^{11}$. Mientras que antes el político era un ciudadano privado que "se vuelve público", supeditando sus actuaciones privadas a su representación pública, hoy el político representa públicamente sus condiciones e intereses privados. Los mismos media se hacen cómplices de la confusión entre los analistas políticos mediáticos, que terminan por convertirse en políticos, y los políticos que actúan como analistas mediáticos. La mediocracia tiene la capacidad de producir nuevos actores políticos y de trasladar las estrellas del espectáculo a la escena de la política ${ }^{12}$. Ha sido tal cambio lo que ha vuelto obscena, en su más etimológico significado, la representación política en la democracia actual; sobre todo en sus actuaciones mediáticas.

En la actualidad se ha producido una imponente confusión entre una representación política, que ya no ejerce un real poder gobernante en nuestras democracias, y una representatividad, incapaz de defender los intereses de los ciudadanos frente a las fuerzas e intereses que realmente gobier-

\footnotetext{
${ }^{10}$ Cfr. Giovannni Sartori, El homo videns. La sociedad teledirigida, Taurus, Madrid, 1998.

${ }^{11}$ Mientras que el político supedita y somete su condición de hombre priva a su actuación política, el "hombre espectáculo", por el contrario, representa, públicamente su condición privada.

${ }^{12}$ Cfr. Francois-Henri de Virieu, La Médiocratie, Flammarion, Paris, 1992 ; Roland Cayrol, Médias et Démocratie: la dérive, Presses de Sciences Po, Paris, 1999 ; Roger-Gérard Schwartzenberg, L'Etat-spectacle : essai sur et contre le star système en politique, Flammarion, Paris, 1977.
} 
nan las democracias modernas. Esto explica que "la mayor amenaza proviene de las instituciones internacionales no democráticas que quieren remplazar la representación política” (Godbout, p.103) por artificios participacionistas.

Sin representación política no sólo la vida parlamentaria sino también el mismo escenario político se vacía de lo que siempre ha sido la "esencia de lo político” (Freund): el debate, la deliberación y el acuerdo; a falta de esta politicidad tanto las prácticas parlamentarias como las políticas gubernamentales quedan reducidas a las dos extremidades más indeseadas, y más allá de lo político: la negociación (mercantil) y el ejercicio de la fuerza (armada) en cuanto prácticas del poder y la dominación. De hecho, tanto el gobierno económico de la política como el recurso a las estrategias bélicas para el gobierno (gobernabilidad o gobernancia) se explican en el fondo por el progresivo desalojo de la representación del escenario político de la democracia.

El ocaso de la representación política ha hecho de las elecciones el peor de todos los simulacros entre las instituciones modernas de la democracia; los ciudadanos siguen obligados a elegir unos representantes, cada vez más incapacitados para ejercer una representación política de los intereses generales y del bien común. Muy por el contrario, se encuentran cada vez más condicionados a representar aquellos intereses de las minorías dominantes como si realmente fueran ellos el interés público y el mejor bien común para toda la sociedad. De otro lado el sistema electoral, muy penetrado por la lógica mercantil, impone masivamente las ofertas electorales sobre las demandas de los ciudadanos, como si sólo aquellas pudieran satisfacer el consumo político de estos. De esta manera, las elecciones siguen legitimando no una representación política sino la representación privada en el seno más público de la democracia, contribuyendo además con este simulacro a distanciar a los ciudadanos de la política y a los representantes de sus supuestos representados. Las reingenierías electorales y del mismo régimen de partidos, que han tenido lugar en las últimas décadas (sobre todo en América Latina), dan cuenta de los intentos por reparar la crisis de la representación política, pero también de adaptar ésta a nuevas circunstancias.

Nada parece haber deslegitimado tanto ideológicamente la representación política, sobre todo entre la opinión pública, como una corriente neo-participacionista de la democracia, una suerte de engañoso "retorno" a la democracia participativa, fenómeno este que además goza del agravante de haber sido promovido no sólo por el mismo discurso neoliberal sino también por los principales organismos del capitalismo internacional (FMI, Banco Mundial, Cooperación internacional); precisamente para acelerar y agravar la crisis de la representación política de la democracia representativa, pero también para sofocar protestas y amainar conflictos. Lo cual prueba en qué medida son los presupuestos ideológicos y políticos de la representación democrática, los que hoy podrían desafiar la hegemonía neoliberal y el imperialismo del mercado capitalista. Sin embargo, los pro- 
motores del participacionismo democrático parecen ignorar que la representación política no es una alternativa a la participación democrática, sino una modalidad de su perfección, y sobre todo parecen desconocer que las causas y razones que hacen hoy fracasar la representación política son las mismas que impedirían una real participación democrática. Pero en el fondo el discurso y prácticas participacionistas sirven sobre todo para promover políticas y estrategias de cooptación por parte de los gobiernos.

En conclusión, el peor fracaso de la representación política consistió en su incapacidad para representar políticamente las demandas y reivindicaciones sociales, que durante los años 80 e incluso 90 protagonizaron los movimientos sociales. Este fracaso se agravó aún más, cuando ya en el curso de los años 90 los movimientos sociales abandonan el ciclo de su conflictividad específica de demandas y reivindicación por una mayor participación social, para entrar en un nuevo ciclo político de protestas contra la exclusión, el empobrecimiento, las políticas y gobiernos neoliberales, y en contra de las mismas instituciones democráticas que los instrumentalizaron. Esta mutación de los movimientos sociales en fuerzas y movilizaciones políticas protestarías radicalizaron la deslegitimación e impugnaciones de todo el sistema de la representación política: partidos y parlamentarios.

Los sucesivos derrocamientos de tres Presidentes de la República entre 1996 y 2005 fueron la mejor prueba no sólo del deterioro de las instituciones democráticas en Ecuador sino también de la fuerza de las movilizaciones protestarías.

\section{Democracia caudillista}

Dos constataciones preliminares: las actuales democracias en todo el mundo, no sólo en América Latina, parecen haber sustituido el principio de la representación política de los ciudadanos por el de la conducción política gobernantes; en este sentido la moderna democracia caudillista responde a causas y características muy diferentes de los caudillismos republicanos del siglo XIX en América Latina.

El concepto de caudillo tiene en América latina un sentido histórico, aplicado a las personalidades políticas que surgieron a partir de las luchas por la independencia; pero significa también una tendencia implícita al desarrollo político en el subcontinente latinoamericano. Esta figura originaria del caudillo político se institucionaliza y reproduce con el modelo presidencialista de las democracias latinoamericanas, lo que constituye la matriz más inmediata de la excesiva personalización del poder del Ejecutivo y el excesivo protagonismo del Presidente en todo el sistema político. Sin embargo, el caudillismo democrático se diferencia de los tradicionales o conservadores, entre otras razones, porque el mandato popular se expresa (institucional) democráticamente, y porque incluso tien- 
de a reproducirse también democráticamente forzando reformas constitucionales.

Además de estos presupuestos histórico-estructurales hay que tener en cuenta un factor más reciente, y que ha contribuido a fortalecer todavía más, pero también a modernizar, los actuales caudillismos democráticos: se trata del mayor poder atribuido a los Ejecutivos y adquirido por los Presidentes en razón del imperativo de la gobernabilidad, que los ha hecho más autónomos respecto de los otros poderes del Estado, liberándolos por ejemplo de las funciones fiscalizadoras o de control del Congreso. Dicha concentración y acumulación de poderes ejecutivos se opera además en detrimento de los poderes y facultades de otras instituciones del régimen democrático. De hecho, la democracia caudillista es un fenómeno directamente proporcional a la desinstitucionalización del Estado y del mismo régimen democrático: sólo la desinstitucionalización política es condición de posibilidad de las democracias caudillistas, y éstas únicamente se consolidan en la medida que precipitan aún más la desinstitucionalización de la democracia.

En este sentido el caudillismo democrático no es lo mismo que un “monarca republicano" (como Michel Debré definió el presidencialismo de de Gaulle) porque, a) el poder de este se encuentra estrictamente limitado por las instituciones; b) su ejercicio del poder está mediatizado por un partido y un gobierno parlamentario. Todo lo contrario ocurre con el caudillo democrático, cuyo poder puede extenderse ilimitadamente a costa del de las instituciones democráticas, y cuyo ejercicio del gobierno es marginal a la mediación parlamentaria y de los partidos. Según esto cabe sostener que el nivel de un caudillismo democrático es proporcional al vacío de un sistema de partidos. En otras palabras, la deslegitimación de los "partidos tradicionales", la oposición a ellos y su impugnación como "partidocracia”, forma parte de la investidura carismática del caudillo democrática por parte del pueblo.

La concentración y acumulación del poder gobernante por parte del Ejecutivo fue resultado en Ecuador de un doble ajuste constitucional: el que tuvo lugar, primero, con la Constitución de 1998 bajo los imperativos de la gobernabilidad y la doble necesidad de conducir las políticas neoliberales y de reprimir o suprimir el ciclo de luchas y protestas sociales provocadas por aquellas políticas; y en segundo lugar, con la Constitución de 2009, que legitimaba una conducción contra-neoliberal del gobierno democrático, pero que sancionaba y legitimaba aún más la concentración y acumulación del poder en el Ejecutivo en detrimento de los poderes despojados al Congreso. Este seguía triplemente precarizado en sus funciones e iniciativas legislativas, de fiscalización y de representación. De hecho, la conversión de la representación en representatividad política beneficiaría sobre todo al Presidente, reforzando su representativismo político con una fuerte personalización del ejercicio de gobierno.

No es tanto la presencia de un caudillo, que hace caudillista una democracia, sino más bien lo contrario: el caudillo es producto de una trans- 
formación de la democracia representativa en democracia caudillista ${ }^{13}$. Esto explica que ni Bucaram ni Gutiérrez dos presidentes con perfiles personales más "caudillistas" que Correa no pudieran consolidar una democracia caudillista, por un defecto de conducción política; precisamente cuando la democracia deja de actuar y regularse por el sistema de representación política (sistema electoral, sistema de partidos, Congreso) para ser gobernada por la conducción política del Ejecutivo y sobre todo del Presidente. Es precisamente en la conducción del gobierno que el Presidente se enviste de representatividad política, asume y en cierto modo usurpa toda la representación nacional ${ }^{14}$. De hecho Correa gana la elección presidencial conduciendo los movimientos de protesta y las movilizaciones sociales, que durante casi dos décadas habían protagonizado la reacción en contra de las políticas neoliberales, y ya como Presidente se propone conducir una política contra-neoliberal, lo que atribuiría a su gobierno un calificativo de nueva izquierda o de socialismo siglo $\mathbf{x x i}^{\mathbf{1 5}}$. Sin embargo, la principal justificación y la mejor definición del moderno caudillismo democrático latinoamericano es "la oposición radical a la política conducida en el país durante la última década llamada de ordenamiento neoliberal”"

Una de las formas que ha adoptado la actual crisis de la democracia en el mundo junto con el decline del Estado-nación es lo que puede conceptualizarse como caudillismos democráticos o más precisamente democracias caudillistas. La democracia caudillista es el resultado de cuatro hechos principales: una acumulación de poderes (legislativos y judiciales) en el Ejecutivo, un desplazamiento de la representación política (parlamentaria) hacia el Presidente con una fuerte personalización (escénica y mediática, populista o clientelar) en la conducción del gobierno, y finalmente sobre todo un alto nivel de precarización y deslegitimación de las instituciones y procesos democráticos. El fenómeno, aunque generalizado, presenta modalidades muy diversas y responde a procesos y factores distintos de acuerdo a los continentes, Norte o Sur, y hasta países. Se precisa por ello distinguir los caudillismos democráticos, de los países desarrollados y de larga tradición parlamentaria, de las democracias caudillistas con una arraigada tradición más presidencialista, como son las latinoamericanas. Y no sólo los perfiles políticos y de su personali-

\footnotetext{
${ }^{13}$ En textos anteriores tratamos ya el "autoritarismo democrático" y la "democracia caudillista” (cf. J. Sánchez Parga, "De la desconsolidación al autoritarismo democráticos”, Ecuador Debate, n. 58, abril 2003; “Fin de la representación política, pugna de representatividades y democracia caudillista”, Ecuador Debate, n. 71, agosto 2007).

14 “...los organismos representativos...no deben participar en la administración pública”(es decir en el ejercicio de gobierno). Lo único, añade John S. Mill, que un grupo puede hacer mejor que un individuo es deliberar" (Consideraciones sobre el gobierno representativo, cap. I, pg. 110).

${ }^{15}$ El Presidente Correa comienza integrando en su gobierno a los principales intérpretes y protagonistas del movimiento "los forajidos", conductores del levantamiento popular que derrocó al Presidente Gutiérrez.

${ }^{16}$ Fernando Molina, “Sept thèses sur le gouvernement d’Evo Morales”, Le Débat, n. 149, mars-avril 2008.
} 
dad o carisma, sino también debido a causas y razones muy particulares propias de los caudillismos democráticos actuales en América Latina. Mientras que las democracias caudillistas del Norte, en los países desarrollados, responden al modelo de dominación neoliberal y de su globalización geopolítica, en los países subdesarrollados del Sur expresan más bien la resistencia a dicho dominio neoliberal y a las fuerzas del capitalismo de mercado.

Sin la mediación de un sistema de partidos no hay posible representación política parlamentaria, ya que ésta se limitaría a reproducir en el mismo Congreso toda la diversidad de fuerzas sociales e intereses en conflicto de toda la sociedad. Por consiguiente sin participación social, que de alguna manera organice las fuerzas e intereses sociales, no hay representación parlamentaria posible, la cual requiere que a su vez un sistema de partidos la estructure, oriente y la haga efectiva. Un sistema de partidos refleja necesariamente una determinada estructura social y la facciona-lización del sistema de partidos es en gran medida una función de la estructura social. Dentro de esta misma contradicción, si cabe hablar de un síndrome constitucionalista, es porque de una u otra manera el caudillismo democrático se instituye en cuanto fundador de un nuevo ordenamiento republicano o democrático; lo que en muchos casos se expresa como una vuelta a los orígenes de la misma república y del Estado nacional, donde supuestamente residen los valores y el modelo más auténtico de la democracia.

En el moderno contexto de la democracia caudillista el clientelismo adopta nuevas formas y racionalidades. En una sociedad de mercado la democracia se encuentra más penetrada por las ofertas de los políticos y gobernantes que por las demandas de los ciudadanos: por una lógica mercantil y una compulsión al consumo las ofertas políticas tienden a convertirse en necesidades para los ciudadanos y finalmente terminan por investir sus propias expectativas y demandas. El clientelismo o penetración del intercambio comercial en las actuaciones y relaciones políticas, siendo un fenómeno antiguo, adopta características particulares en una sociedad de mercado como la actual, y no es por ello ajeno al caudillismo democrático, en la medida que propicia y promueve el síndrome clientelar tanto por su excesiva personalización “patronal” con el caudillo como por la sustitución de la representación política por las relaciones clientelares, y su difusión por los organismos estatales de la democracia caudillista; la cual tiende a prolongar el clientelismo electoral, que procura votos, en un clientelismo gubernamental, que asegure apoyos a las políticas del Ejecutivo.

El clientelismo en la democracia caudillista se encuentra estrechamente articulado a otros fenómenos políticos muy singulares y que contribuyen a caracterizar dicho modelo estatal y gubernamental: la ideología y prácticas participacionistas están muy ligadas, por un lado a las políticas redistributivas de los actuales gobiernos con amplios y efectivos programas sociales, y por otro lado a dispositivos y procedimientos de coopta- 
ción, que sirven para integrar las dinámicas e iniciativas de participación en organismos e instituciones del mismo Estado.

\section{De movimientos sociales a movilizaciones y desmovilizaciones sociales}

No es casual que la “tercera ola” de democratización en el mundo, que en América Latina llega en los años 80, casi con una década de retraso, coincida con la emergencia de los "nuevos movimientos sociales", precisamente cuando el mundo asiste a una extraordinaria expansión económica, a un gran impulso del desarrollo y la cooperación con amplios efectos distributivos: la década de los $70^{17}$. Esto no significa una directa y necesaria asociación entre democracia y un determinado modelo de crecimiento económico, sino con el específico efecto distributivo que puede tener un determinado modelo de producción económica ${ }^{18}$. Y obviamente también con un determinado régimen político o de Estado con disposiciones suficientes incluso institucionales para garantizar una redistribución capaz de compensar las limitaciones estructurales o históricas de distribución propias a todo modelo de producción económica.

Los “movimientos sociales” no se constituyen sino en el conflicto y en un escenario democrático; se forman y actúan conflictivamente, ya que las prácticas y discursos en los que se constituyen se enfrentan con otros actores sociales en sus respectivas disputas por mayor participación social. Para Touraine "el movimiento social es la acción... socialmente conflictual” (1984:152), no sólo porque se constituye en conflicto con otros actores y fuerzas sociales, sino también porque provoca conflictos transformando el escenario y correlaciones de fuerzas ya existentes, porque se trata siempre de acciones no sólo ligadas al cambio, sino que combaten el mismo cambio en razón de un nuevo orden. Es por consiguiente también el carácter esencialmente reivindicativo lo que hace conflictivo el movimiento social.

Ahora bien, la conflictividad social generada por los movimientos sociales tendrá muy diferentes intensidades, frecuencias y violencias ocasionales dependiendo: a) del tipo de estructura social más o menos igualitaria o inequitativa, capaz de permitir una mayor o menor distribución de la riqueza; b) de una clase media más o menos amplia, consolidada y hegemónica, capaz de atenuar las contradicciones entre las diferencias más extremas de la sociedad y de identificar mejor ese interés o bien co-

\footnotetext{
17 "Sólo en las sociedades democráticas se forman los movimientos sociales, pues la libre oferta política obliga a cada actor social a buscar el bien común al mismo tiempo que la defensa de intereses particulares” (A. Touraine, 1994:88). Cfr. Samuel Huntington, 1991.

${ }^{18}$ De la misma manera habría que precisar la posición contraria de "la cruel decisión entre rápida o sostenida expansión económica y proceso democrático”. Para un balance sobre este debate se puede consultar Adam Przeworski, "The neoliberal Fallacy”, Journal of Democracy, vol. 3, n.3, 1992.
} 
mún más ampliamente compartido; c) un sistema político, partidos y actores políticos más o menos capaces de representar políticamente el conflicto y sus reivindicaciones, las demandas de los "movimientos sociales"; d) un Estado Social de Derecho y gobiernos con políticas sociales capaces de implementar una amplia y efectiva redistribución social ${ }^{19}$.

En Ecuador, y en general en América Latina, estos factores sociopolíticos influyeron tanto en la intensidad de los conflictos sociales como en el fracaso de sus reivindicaciones durante la “década perdida” de los 80. En primer lugar, las desigualdades sociales eran tan radicales e irreductibles, que impidiendo en mayor o menor escala toda posible distribución de riqueza, bloquearon y frustraron las demandas de más y mejor participación social protagonizadas por los "movimientos sociales"; en segundo lugar, la ausencia de una sociedad política, de un sistema de partidos y de un Congreso, suficientemente fuertes e independientes de las fuerzas e intereses de las clases dominantes, no sometidos a las oligarquías dominantes, hizo imposible una real representación política de las reivindicaciones y conflictos sociales; en tercer lugar, tampoco los gobiernos de la "transición democrática”, ni el Estado en su organización político administrativa fueron capaces de responder a las reivindicaciones expresadas en los conflictos y protagonizadas por los “movimientos sociales", ni mucho menos de implementar políticas redistributivas y programas sociales, que atenuaran dichos conflictos y satisficieran en parte dichas reivindicaciones. Pero esta crisis de conflictividad social se encuentra ya afectada en la década de los 80 por los impactos del nuevo modelo neoliberal de acumulación capitalista.

En este contexto se van definiendo los distintos movimientos sociales de acuerdo a la frecuencia de sus actuaciones. Así en Ecuador entre 1984 y 1995 el movimiento gremial protagoniza el 23.7\% de toda la conflictividad social, seguido por el movimiento de los trabajadores, $21.1 \%$, el movimiento barrial, $18.1 \%$, el cívico regional, $11.5 \%$, el movimiento estudiantil, 7.9\%, el movimiento sindical, 3.2\%, el movimiento campesino, $2.9 \%$. Hay otros movimientos sociales como el indígena, que acusan una débil frecuencia conflictiva $(0.9 \%)$, pero cuyo grado de organización, dinámica de sus movilizaciones e intensidad de su lucha, la amplitud de sus bases y fuerza de sus reivindicaciones lo han convertido en el movimiento social más representativo de la escena nacional entre los 80 y los $90^{20}$. Otros en cambio, como el movimiento de mujeres, se constituyó más bien con actuaciones y discursos de bajo nivel de movilización, sin recurrir a los convencionales "repertorios del conflicto" (paros y huelgas, marchas y bloqueos, etc.).

19 En este sentido declara Touraine que "los movimientos sociales serían reacciones al derrumbe de uno de los principales aspectos del sistema social, cuando las instituciones políticas no tienen la capacidad de operar los necesarios ajustes" (La parole et le sang. Politique et Société en Amérique Latine, Edit. Odile Jacob, Paris, 1988: 161).

20 Cfr. J. Sánchez Parga, Las cifras del conflicto social en Ecuador. 1980-1995, CAAP, Quito, 1996. 


\section{Impacto económico político neoliberal en los movimientos sociales}

El nuevo ciclo del capital financiero con la dominación neoliberal instaura el poder de los accionistas, propietarios de capital, y no ya de los propietarios de los medios de producción ${ }^{21}$. Aunque el primer impacto de este cambio de modelo económico en la democracia ecuatoriana tuvo su principal efecto en la deuda externa con el pago de sus nuevos y exorbitantes intereses, y en los programas de ajuste estructural, el futuro destino de la democracia durante las tres décadas siguientes quedaría marcado por el neoliberalismo económico: la finanza hecha ley.

Esta nueva fase del modo de producción capitalista basado en la concentración y acumulación de riqueza es no-distributivo. Cualquier distribución contradeciría la lógica de acumulación del capital. Este nuevo modelo capitalista de mercado que se impone a nivel global tiene tres consecuencias socio-políticas, que directamente influyen en conflicto social: a) liquida el Estado social de derecho (keynesiano) re-distributivo; b) excluye toda posible participación social en la nueva forma de "crecimiento económico", el cual sólo es posible a condición de mayor inequidad social; c) desarma y deslegitima, por consiguiente, todos los conflictos reivindicativos y las demandas de los “movimientos sociales" por una mayor participación social. Como "cada fase del capitalismo supone una relación entre Estado y economía, pero también entre Estado y masas, modificaciones en el patrón de acumulación pero también en el patrón de hegemonía" (Portantiero, 1988:14) y de dominación, de igual manera el conflicto social quedará atravesado por una contradicción entre gobiernos democráticos y políticas económicas neoliberales.

Esta contradicción en la que se encuentra atrapada una conflictividad social con todas sus intensidades y diversas morfologías tenderá a configurar situaciones revolucionarias sin revolución, desestabilizadoras de la democracia sin ser antidemocráticas, anti-institucionalistas y desinstitucionalizadoras, sumiendo las democracias en una violencia y desintitucionalización sin límites, pero capaces de sobrevivir dentro de una creciente criminalización de la sociedad y de conflictos armados. Tales contradicciones hacen que "la democracia amenazada por todos los lados ya no tenga una imagen clara de sí misma” (Touraine, 1994: 275).

Si en un principio la transformación del conflicto se tradujo en un "aumento de la capacidad defensiva y disminución de la capacidad de acción ofensiva autónoma” (Touraine, 1987: 89), en la actualidad asistimos a una erosión de esta misma conflictividad social, al desgastarse las capacidades de resistencia frente a los procesos de exclusión, empobrecimiento y

${ }^{21}$ El Dow Jones industrial, el indicador financiero más representativo de la bolsa de valores de Wall Street pasa de 1.000 puntos en 1979 a 15.000 en el año 2008: Fuente: Dow Jones \& Company (www.dowjones.com). 
aumento de las desigualdades. Esto no significa una reducción de la protesta sino más bien que "la fuerte demanda social se conjuga estrechamente con una reducida capacidad de acción política”; ya que los mismos conflictos no disponen de los espacios e instrumentos, recursos e instituciones para lograr cambio alguno.

Mientras que el régimen de explotación del trabajo por el capital productivo permitía reivindicaciones salariales y demandas de una mayor participación en los productos (bienes y servicios) de la sociedad, bajo el nuevo régimen de exclusión propio de la acumulación y concentración de riqueza, no queda margen para discursos y luchas reivindicativas; sólo la protestas e impugnaciones reactivas darán lugar a las futuras movilizaciones sociales. De esta manera, "la política del conflicto varía y se transforma en estrecha correspondencia con los cambios del poder político, y que se organiza tanto al interior como al exterior de las mismas instituciones” (Ch. Tilly \& S. Tarrow, 2008:91). De hecho, uno de los conflictos que acusa un mayor y más claro decline es precisamente el más reivindicativo en el ámbito de la producción y distribución económica: el salarial.

\section{Evolución Conflicto salarial (número, \% total conflictos)}

\begin{tabular}{|c|c|c|c|}
\hline Período & $1984-1992$ & $1993-1998$ & $1999-2006$ \\
\hline Número & 282 & 412 & 426 \\
\hline \% Total & $24.5 \%$ & $16.5 \%$ & $13.5 \%$ \\
\hline
\end{tabular}

Fuente: Observatorio Conflictividad. CAAP. Quito. Revista Ecuador Debate

Son los gobiernos democráticos, implementando políticas y programas neoliberales u “oligárquicos”, los que inician un nuevo ciclo político de la economía con el gobierno económico de la política; en el fondo, los gobiernos democráticos son gobernados por las fuerzas e intereses del capital global, y por los dictámenes del FMI, del Banco Mundial, OMC, el BID y todos los otros organismos del desarrollo financiero y de la cooperación internacional ${ }^{22}$. De esta manera los mismos gobiernos democráticos han supeditado despóticamente la razón de Estado a la razón de Mercado, y por primera vez "en la historia económica contemporánea el cruce de las condicionalidades internacionales financieras restringe el manejo interno de la política económica y asegura las reglas del juego internacionales. En el plano económico se podría hablar de un solo gobierno central con matices municipales"23. Este modelo de gobierno económico de la democracia, que supuso una pérdida de control por parte de los gobiernos de las economías nacionales, y una nueva forma de imperialismo económico ejer-

${ }^{22}$ Cfr. J. Sánchez Parga, “El ciclo político de la economía y el gobierno económico de la política”, Ecuador Debate, n. 55, abril 2002.

${ }^{23}$ Oscar Ugarteche, El falso dilema. América Latina en la economía global, Nueva Sociedad, Caracas, 1997:199. 
cido a través de los gobiernos democráticos, no sólo tuvo consecuencias destructoras de las instituciones democráticas, asestando un duro golpe a las instituciones de la representación política sino también a las capacidades redistributivas de gobiernos y Estado; también desarmó las mismas fuerzas reivindicativas de las luchas y de los movimientos sociales ${ }^{24}$.

Así se establece una situación política aparentemente contradictoria: un régimen democrático con gobiernos y políticas oligárquicos; considerando que la oligarquía no es el gobierno de unos pocos ricos sino un gobierno "en beneficio de los intereses de unos pocos ricos" por parte de otros: la oligarquía no necesita ejercer el gobierno, pues basta que sus representantes políticos gobiernen en representación de sus intereses económicos. La democracia garantiza así que dicho gobierno en beneficio de unos pocos aparezca como si fuera en beneficio del bien común ${ }^{25}$.

Esta tensa inestabilidad entre conflictos sociales e instituciones democráticas, que caracteriza la década de la transición (años 80), se quiebra en el curso de los años 90, cuando los conflictos reivindicativos se transforman en luchas sociales de protesta contra las instituciones democráticas, dando lugar a la fase que hemos denominado desconsolidación de la democracia. Dos serán las principales impugnaciones: contra el sistema de la representación política (electoral, de partidos y Congreso), incapaz de responder a las reivindicaciones de los “movimientos sociales”, y contra los Gobiernos y Presidentes por sus políticas económicas neoliberales.

En América Latina como en Ecuador los movimientos sociales fueron más políticos que sociales. Al no contar con efectivas instituciones democráticas de la representación política (sistema electoral, de partidos y Congreso), ellos mismos estaban forzados a actuar políticamente. Por esta razón, más que "un decline de los movimientos sociales" (Touraine, 1987:273) por falta de condiciones reivindicativas, ya durante la década de los 90 las movilizaciones políticas ocuparán el proscenio de las luchas sociales.

Nos encontraríamos en presencia de movimientos sociales sin actores sociales, de “actores sin acción social”, ya que sus actuaciones no tienen efecto de sociedad ni comportan cambio alguno en ella. De otro lado, en la medida que se hacen más reactivos que proactivos, los movimientos sociales se vuelven políticos, actuando como una fuerza política o grupo de presión (Touraine, 1993:308). Por eso los movimientos sociales se definirán cada vez más por la tensión entre la defensa de sus intereses y la conquista del poder; por la paradoja de que las conquistas políticas no conlle-

${ }^{24}$ C. Palloix, "Crise et nouvelles formes d'imperialisme. Economie du crédit international et extensions internationales du salariat”, en J. L. Reiffers, Economie et finances internationales, Dunod, París, 1982.

${ }^{25}$ Ya Aristóteles había notado que nada garantiza mejor en un régimen democrático el gobierno "en beneficio de los intereses oligárquicos" que la separación entre los cargos políticos y la participación en la riqueza (Politica, III, v, 1279b 8; V, vii, 1308b 38ss). 
ven la defensa de sus intereses sociales. De este proceso dos fueron las consecuencias a partir de los 90: muchos movimientos sociales se reconvirtieron al espacio más privado de las ONG's o se transformaron en fuerzas políticas, adoptando la forma de partido. Fue el caso del movimiento indígena ecuatoriano, el más importante de los movimientos sociales (por su dinámica y diversidad organizativa, la amplitud de sus bases comunales, la fuerza de sus reivindicaciones, su específica identidad étnica y sus capacidades de movilización), el cual hizo de Pachakutik su "brazo político".

\section{De los movimientos sociales al ciclo político de la protesta}

Una nueva forma de lucha, desde hace más de una década, agita la mayor parte de los países, crispa los escenarios socio-políticos, deslegitima las democracias, desestabiliza gobiernos y llega incluso a derrocar presidentes. La protesta, bajo su apariencia defensiva y “reactiva”, es portadora de insospechada violencia y parece haber sustituido la anterior conflictividad social, tan fundamental para la democracia como era constitutiva de los movimientos sociales. ¿A qué nuevo orden y desorden responde el actual ciclo político de la protesta? ¿Cuáles son sus alcances globales?

Las luchas sociales se articulan sobre una doble y fundamental lógica y dinámica: las reivindicaciones por la igualdad (demand for equalty) y protestas contra la desigualdad (protest again inequality); el espacio sociopolítico propicio para la primera forma de conflictividad es obviamente la democracia; la segunda forma de conflicto surge bajo sociedades y gobiernos oligárquicos ${ }^{26}$. Por eso, aunque ambas formas de lucha pueden combinarse el marco socio-económico y político impone más bien un ciclo de lucha sobre el otro.

En Ecuador la transición de los conflictos sociales a las movilizaciones de protesta pudo observarse ya a finales de la década de los 90 a partir de los datos del Observatorio de la conflictividad: los conflictos asociados a demandas y reivindicaciones ya sea salariales, por mayor participación social y mejores condiciones de vida, o a exigencias más específicas fueron disminuyendo, en la medida que aumentaban nuevas formas de luchas sociales de carácter protestatarios, más reactivas, en contra de los gobiernos y sus políticas y en particular contra los programas económicos neoliberales. El cambio se observó no sólo en los contenidos o razones de la lucha social sino también en las formas o "repertorios" de su beligerancia, y en las estrategias e identidad de sus actores. Lo que se conceptualizó como una mutación de los "movimientos sociales" en movilizaciones socio-políticas ${ }^{27}$.

${ }^{26}$ Cfr. Amartya Sen, Inequality Reexamined, Clarendon Press Oxford, London, 1992.

27 Cfr. J. Sánchez Parga, “Transformaciones del conflicto, decline de los movimientos sociales y teoría del desgobierno”, Ecuador Debate, n. 53, agosto 2001. 
La literatura sobre la protesta en América Latina, a partir de la obra de Susan Eckstein (1989) comienza a desarrollarse sobre todo desde la crisis argentina del 2002. En este sentido la reconstrucción histórica de este período por la obra de Schuster es muy representativa de cómo la caracterización de una coyuntura particular puede responder a un nuevo concepto de las luchas sociales ${ }^{28}$. Aunque elaboraciones teóricas pioneras se habrían iniciado ya con la década de los 80 y sobre todo en los años $90^{29}$. Una obra más reciente de CLACSO trata de precisar la dimensión reactiva del ciclo de protesta política y sus efectos “contra-hegemónicos” en la conformación de nuevos gobiernos contra-neoliberales sobre todo en América del Sur. Lo que en el caso ecuatoriano resulta muy evidente, ya que el movimiento Alianza País y su conducción por el Presidente Correa serían no sólo producto de dicho movimiento de protesta, que se consolida durante la última década, sino también su expresión respecto de la hegemonía neoliberal.

En América Latina más que en otras regiones del mundo la protesta como forma reactiva de lucha ha estado presente en los mismos conflictos sociales, invistiéndolos de una politicidad variable y convirtiendo siempre al Estado en su adversario indirecto o terminal ${ }^{30}$. Esto explicaría no sólo que en América Latina las luchas hayan sido por lo general más políticas que sociales (según las conclusiones de Touraine), sino también que el actual ciclo político de la protesta, en el contexto de un re-ordenamiento global del mundo, haya tenido unas formas, violencias y alcances mayores que en otras regiones.

Por esta razón, ha sostenido repetidamente Touraine, los movimientos sociales en América Latina han sido siempre más políticos que sociales, dando lugar a una fuerte politización de la acción colectiva; “a moviliza-

${ }^{28}$ Federico Schuster et al. , Transformaciones de la protesta social en Argentina 19892003, Documentos de Trabajo del Instituto de Investigación Gino Germani, n. 48, 2006. Cfr. Norma Garriaca, La protesta social en la Argentina. Transformaciones económicas y crisis social en el interior del país, Alianza, Buenos Aires, 2001; Javier Auyero, La protesta: retratos de la beligerancia popular en la Argentina democrática, Libros del Rojas, Buenos Aires, 2002; Adrián Scribano \& Federico Schuster, Protesta social en la Argentina de 2001: entre la normalidad y la ruptura. OSAL (Observatorio Social de América latina), vol. 5, 2002; Gabriela Delamata, “De los ‘estallidos’ provinciales a la generalización de las protestas en Argentina. Perspectivas y contexto en la significación de las nuevas protestas”, Nueva Sociedad, n. 182, 2002.

${ }^{29} \mathrm{Cfr}$. Sidney Tarrow, Struggling to reform: social movements and policy during cycles of protest, Ithaca: Western Societies Program Center for International Studies Cornell University, 1983; J. Craig Jenkins \& Bert Klandermans (eds.), The politics of social protest: Comparatives on states and social movements, University of Minnesota, Minneapolis, 1995. 30 "Latin America led other world regions in what, nevertheless, was an unprecedented wave of international protest; unprecedented in the scope and essentially singular cause of a global protest analogous to earlier national strikes waves..." (John Walton, "Debt, Protest and the State in Latin America”, en Susan Eckstein (edit.), Power and Popular Protest. Latin American Social Movements, University of California Press, London, 1989). 
ciones sociales sin real movimiento social”31. Estos fenómenos contribuyeron no sólo a una tal radicalización política del conflicto social, que en determinadas circunstancias rebasará los umbrales del orden e institucionalidad democráticos, sino también a su progresiva politización. Y por eso el conflicto social reivindicativo y democrático terminará volviéndose conflicto antioligárquico, contra la misma clase política, contra los gobiernos y sus políticas, y finalmente contra el mismo Estado y hasta la misma democracia. Es necesario constatar que "la política del conflicto varía y se transforma en estrecha correspondencia con los cambios del poder político, y que se organiza tanto al interior como al exterior de las instancias institucionales”32.

La transición del conflicto social al ciclo político de la protesta aparece claramente identificada en el paso del gobierno social-demócrata de Borja (1988-92) al gobierno neoliberal de Sixto Durán (1992-1996). Aunque ya las medidas del ajuste estructural habían generado los primeros brotes de protesta, sólo cuando el programa neoliberal se consolida en cuanto política de gobierno, como un gobierno económico de la política, se opera un aumento constante de las protestas y un decline de la conflictividad reivindicativa (huelgas y paros).

Lentamente pero de manera progresiva la protesta socio-política se impone con mayor frecuencia sobre los conflictos reivindicativos, cuya más fuertes expresión son las huelgas y paros. La transición de la lucha reivindicativa a la lucha protestaria (de los años 80 a los 90) se encuentra muy marcada y enmarcada por el decline del conflicto laboral y sindical: cuando los conflictos generados por la explotación se convierten en conflictos contra la exclusión. Incluso en países sin una importante masa asalariada y sin gran tradición sindical puede visualizarse con claridad cómo las formas más características de las reivindicaciones salariales y laborales se transforman en estallidos de violencia contra los despidos laborales. No sólo el nuevo modelo de acumulación capitalista sino también las reformas del Código del Trabajo contribuyen a minar las bases del conflicto laboral, para dar paso a las movilizaciones de la protesta.

\section{Cambios Porcentajes de la conflictividad}

\begin{tabular}{|l|l|l|l|l|l|l|l|l|l|l|l|}
\hline Años & 1996 & 1997 & 1998 & 1999 & 2000 & 2001 & 2002 & 2003 & 2004 & 2005 & 2006 \\
\hline Huelgas & $26 \%$ & $18 \%$ & $16 \%$ & $17 \%$ & $13 \%$ & $28 \%$ & $24 \%$ & $29 \%$ & $21 \%$ & $13 \%$ & $14 \%$ \\
\hline Protest. & $21 \%$ & $14 \%$ & $18 \%$ & $15 \%$ & $21 \%$ & $16 \%$ & $27 \%$ & $20 \%$ & $35 \%$ & $26 \%$ & $30 \%$ \\
\hline
\end{tabular}

Fuente: Observatorio Conflictividad. Revista Ecuador Debate.

${ }^{31}$ Alain Touraine (Actores sociales y sistemas políticos en América Latina, PREALC, Santiago, 1987:87) no dejará de insistir en que "en América latina no se forman fácilmente actores sociales... se forman actores políticos” (o. c., p.131).

${ }^{32}$ Cfr. Charles Tilly \& Sidney Tarrow, Politique(s) du conflit, Sciences Po, Paris, 2008:91. 
Es progresivamente que el ciclo político de la protesta se impone con mayor frecuencia a los conflictos reivindicativos, superando el porcentaje dentro de la conflictividad general. En la protesta se encuentran cifradas en primer lugar las dinámicas reactivas y frustraciones frente al fracaso de la conflictividad reivindicativa; en segundo lugar la impugnación creciente contra las políticas neoliberales de los gobiernos; en tercer lugar una reacción en contra de una democracia cada vez más deslegitimada.

\section{De la desmovilización social a la violencia social}

La lenta y larga transformación del conflicto social en luchas de protesta (de movimientos sociales en movilizaciones políticas) parece prolongarse en un nuevo proceso, que supone una radical mutación de las mismas luchas sociales: el decline de toda forma de conflictividad socio-política, incluidas las movilizaciones protestatarias. Este decline de las luchas sociales resulta en la actual modernidad extremadamente contradictorio, pues las diferencias económicas crecen y las desigualdades sociales se agravan, lo que debería más bien traducirse en mayor y más intensan tensiones y confrontaciones al interior de la sociedad. Una razón explica este fenómeno: mientras que el proceso de transformación de los conflictos sociales en luchas protestatarias responde a un cambio en el modelo del desarrollo capitalista y en el mismo sistema político (fin del Estado keynesiano y “desconsolidación” de la democracia), el decline de las luchas sociales en sus dos formas, reivindicativas y de protesta, son producto de un proceso de larga duración y de un cambio en el mismo modelo de sociedad: de una sociedad societal a una sociedad de mercado.

De hecho, se trata de dos procesos en parte sucesivos y en parte paralelos: a medida que se consolida y comienza a desgastarse el ciclo de la protesta se inicia ya el decline de las luchas sociales y de las misma conflictividad política. Las causas tendientes a suprimir todas las luchas sociales, son tan estructurales a la misma sociedad que afectan todas las formas de la conflictividad. Puesto que la conflictividad social ha dado lugar a una conflictividad política, la transformación que se pone de manifiesto desde hace una década explica no sólo el decline de los conflictos sociales sino también el de los políticos.

La reducción de toda la conflictividad social en general se mantiene constante desde 1998, a excepción de un repunte de sus frecuencia los años 2005 y 2006, en el lapso de una coyuntura muy particular: las movilizaciones sociales y levantamiento políticos que provocaron la última caída presidencial de Gutiérrez. 


\section{Decline de la conflictividad}

\begin{tabular}{|c|c|c|}
\hline AÑOS & $\mathbf{N}^{0}$ CONFLICTOS & TCA $\%$ \\
\hline 1,998 & 689 & \\
\hline 1,999 & 754 & 9.4 \\
\hline 2,000 & 641 & -15.0 \\
\hline 2,001 & 484 & -35.8 \\
\hline 2,002 & 261 & -46.1 \\
\hline 2,003 & 277 & 6.1 \\
\hline 2,004 & 255 & -7.9 \\
\hline 2,005 & 487 & 91.0 \\
\hline 2,006 & 399 & -18.1 \\
\hline 2,007 & 379 & -5.0 \\
\hline
\end{tabular}

FUENTE: Observatorio Conflicto

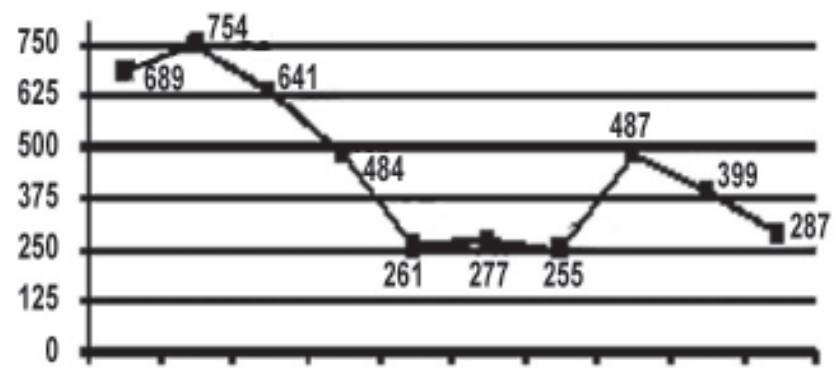

1998199920002001200220032004200520062007

El análisis de la conflictividad social en un determinado momento permitió comprender la transformación de los actores de la lucha social, el paso de los movimientos sociales a las movilizaciones políticas, y posteriormente condujo a entender una alteración dentro de la misma lucha social, con la sustitución del conflicto por la protesta. Lo que hoy se plantea es un cambio más estructural, y por eso mismo menos visible, que afecta no ya los actores y contenidos de la lucha social sino la misma sociedad en sus relaciones e instituciones sociales: el cambio del conflicto en violencia social. Se trata de un fenómeno no exclusivo del Ecuador ni propio de América Latina; por eso las explicaciones del "conflicto eludido" en otras 
regiones pueden servir para corroborar y complementar las interpretaciones de un hecho con alcances globales ${ }^{33}$.

El decline de toda la conflictividad social protagonizada por los diferentes sectores y grupos sociales constituye el mejor exponente e indicador de la desmovilización de dichos actores sociales ${ }^{34}$. La desmovilización laboral se encuentra particularmente acentuada y afecta no sólo la reducción de los conflictos salariales y laborales, tanto del sector privado como público, sino también los conflictos protagonizados por los sindicatos y los gremios, que pasan de 71 en el año 1997 a 22 en el 2006; en el mismo período las huelgas y paros se reducen de 119 y 129 en 1998 y 1999 a 24 y 23 en los años 2007 y 2008 respectivamente. La misma desmovilización afecta al movimiento campesino y al movimiento indígena, que de 28 y 25 conflictos respectivamente en 1998 pasan a 14 y 15 en el año 2008. No menos espectacular es la disminución de los conflictos conducidos por los movimientos barriales, que de 142 en 1998 pasan a 33 en 2008; así como las movilizaciones de las organizaciones barriales, que caen de 119 en 1998 a 30 en 2008. Y análogo es el caso del movimiento estudiantil, cuyas manifestaciones se reducen de 23 en 1998 a 9 en 2008, y de las movilizaciones cívico-regionales, que de 109 en 1998 disminuyen a 34 en 2008.

Tras haber demostrado el decline de las luchas sociales, en sus formas reivindicativas tanto como protestatarias, y después de mostrar que dicho decline, además de ser un fenómeno generalizado y observado en otras sociedades muy distintas, responde a factores propios de la moderna sociedad de mercado y del nuevo orden global del mundo, se ha probado también la correlación entre el decline de la conflictividad social y el auge de las violencias sociales. A partir de las opuestas y hasta contradictorias características entre ambos fenómenos.

Es clara la argumentación que explica este fenómeno. La conflictividad y luchas sociales en una sociedad se reducen y tienden a desaparecer sólo por dos razones: o bien son reprimidas por las violencias políticas de un régimen autoritario, que recurre a un ejercicio extremo de la fuerza o bien son suprimidas por las violencias sociales generadas por un determinado modelo de sociedad, tendiente a atrofiar y eliminar todas las formas de luchas y movilizaciones sociales. De hecho, en las sociedades actuales, por muy autoritarios que parezcan se muestren los gobiernos democráticos, son estas violencias sociales, producto de la ruptura de vínculos sociales, las que tienden a generar víctimas y victimarios y no tanto enemigos y adversarios de las luchas sociales.

\footnotetext{
${ }^{33}$ Roser Cussó et al., Le conflit social éludé, Academia Bruylant, Louvain - La - Neuve, 2008.

${ }^{34}$ Los datos estadísticos han sido tomados del Observatorio del Conflicto, publicados en la revista Ecuador Debate; las elaboraciones e interpretación de dichos datos forman parte de un próxima publicación del CAAP, Quito, con el título Transformaciones políticas, decline de los conflictos y auge de las violencias: Ecuador 1998 - 2008.
} 


\section{Bibliografia}

Aristóteles, Politics (Edic. Bil.) (1977), Harvard University Press, London.

Auyero, Javier Auyero (2002), La protesta: retratos de la beligerancia popular en la Argentina democrática, Libros del Rojas, Buenos Aires.

Baumier, Matthieu (2007), La démocratie totalitaire. Penser la modernité post-démocratique, Presses de la Renaissance, Paris, 2007.

Bredin, Jean - Denis (1988), Seiyès. La clè de la Revolution francaise, Edit. de Fallois, Paris.

CIS / AECI / (1998) Universidad de Salamanca, Elites parlamentarias. Ecuador, vol. 4, Madrid.

CLACSO (2003), Latinbarómetro. Informe. Resumen. La democracia y la economía, www.latinbarometro.org, octubre.

Cusso, Roser et al. (2008), Le conflit éludé, Academia Bruylant, Louvain la Neuve.

Delamatta, Gabriela (2002), “De los ‘estallidos’ provinciales a la generalización de las protestas en Argentina. Perspectivas y contexto en la significación de las nuevas protestas”, Nueva Sociedad, n. 182.

Freund, Julien (1986), L'essence du politique, Ed. Sirey, Paris.

Garriaca, Norma (2001), La protesta social en la Argentina. Transformaciones económicas y crisis social en el interior del país, Alianza, Buenos Aires.

Huntington, Samuel (1991), The Third Wave: Democratization in the Late Twentieth Century, University Oklahoma Press.

Jenkins, J. Craig Jenkins \& Klandermans, Bert Klandermans (eds.) 1995, The politics of social protest: Comparatives on states and social movements, University Minnesota, Minneapolis.

Linz, Juan L. (1994), "Presidential or Parliamentary Democracy”, en Juan J. Linz \& Arturo Valenzuela, The Failure of Presidential Democracy, The Johns Hopkins University Press, Blatimore and London.

Mill, John Stuart (2001), Consideraciones sobre el gobierno representativo (1860), Edit. Alianza, Madrid.

Molina, Fernando (2008), “Sept thèses sur le gouvernement d'Evo Morales”, Le Débat, n. 149, mars-avril. 
O’Donnell, Guillermo (1994), “Delegative Democracy”, Journal of Democracy, n. 5.

Palloix, C. (1982), “Crise et nouvelles formes d'imperialisme. Economie du crédit international et extensions internationales du salariat”, en J. L. Reiffers, Economie et finances internationales, Dunod, Paris, 1982.

Portantiero, J.C. (1988), La producción de un orden. Ensayo sobre la democracia entre Estado y sociedad, Nueva Visión, Buenos Aires.

Przeworski, Adam (1992), “The neoliberal Fallacy”, Journal of Democracy, vol. 3, n.3.

Rousseau, J. - J. (1905), Du Contrat Social Oeuvres completes.

Sánchez Parga, J. (1996), Las cifras del conflicto social. Ecuador 19801995. CAAP, Quito.

Ídem (2000), “Pugna de intereses y desconsolidación de la democracia” en Ecuador Debate, n. 51 agosto.

Ídem (2001), “Transformaciones del conflicto, decline de los movimientos sociales y teoría del desgobierno”, en Ecuador Debate, n. 53, agosto.

Ídem (2002), El ciclo político de la economía y el gobierno económico de la política”, Ecuador Debate, n. 55, abril.

Ídem (2003), “De la desconsolidación al autoritarismo democráticos”, Ecuador Debate, n. 58, abril.

Ídem (2004), "Por qué se deslegitima la democracia? El desorden democrático”, en Ecuador Debate, n. 62 agosto.

Ídem (2005), “Sin (creciente) inequidad no hay crecimiento económico”, Socialismo y Participación, n.93, Lima.

Ídem (2007) “Fin de la representación política, pugna de representatividades y democracia caudillista”, Ecuador Debate, n. 71, agosto.

Sartori, Giovanni (1998), El homo videns. La sociedad teledirigida, Taurus, Madrid.

Schmitt, Carl (1963), Die Diktatur, Berlin.

Schuster, Federico et al. (2006), Transformaciones de la protesta social en Argentina 1989-2003, Documentos de Trabajo del Instituto de Investigación Gino Germani, n. 48. 
Schwartzenberg, Roger-Gérard (1977), L'Etat-spectacle : essai sur et contre le star système en politique, Flammarion, Paris.

Scribano, Adrián \& Schuster, Federico (2002), Protesta social en la Argentina de 2001: entre la normalidad y la ruptura. OSAL (Observatorio Social de América latina), vol. 5.

Sen, Amartya (1992), Inequality Reexamined, Clarendon Press Oxford, London.

Tarrow, Sidney (1983), Struggling to reform: social movements and policy during cycles of protest, Ithaca: Western Societies Program Center for International Studies Cornell University.

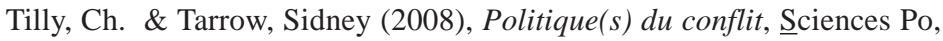
Paris.

Tussel, Javier (1997), La revolución posdemocrática, Edic. Nobel, Oviedo.

Ugarteche, Óscar (1997), El falso dilema. América Latina en la economía global, Nueva Sociedad, Caracas.

Virieu, François-Henri de (1999), La Médiocratie, Flammarion, Paris, 1992 ; Roland Cayrol, Médias et Démocratie: la dérive, Presses de Sciences Po, Paris.

Walton, John (1989), "Debt, Protest and the State in Latin America”, en Susan Eckstein (edit.), Power and Popular Protest. Latin American Social Movements, University of California Press, London. 